\title{
Pengereman Dinamik Motor Induksi 3 Fase 220V/380V
}

\author{
Moch. Faishol Yusron ${ }^{1)}$, Joko ${ }^{2)}$ \\ 1) Mahasiswa D3 Teknik Listrik Jurusan Teknik Elektro F. Teknik Unesa Surabaya, faishal_yusron@yahoo.com \\ 2) Dosen Jurusan Teknik Elektro Fakultas Teknik Unesa Surabaya, unesa_joko@yahoo.com
}

\section{ABSTRAK}

Alat pengendali motor listrik sangat berpengaruh terhadap kelangsungan proses produksi baik pengendalian pada saat mulai, pengendalian kecepatan (putaran), pengendalian pengereman dan pengendalian pada saat berhenti. Khususnya pengendalian motor induksi pada saat pengereman, diperlukan sistem pengendali yang handal, efektif, efesien dan dapat bekerja secara terus-menerus. Penelitian ini merupakan hasil kajian tentang rancang bangun pembuatan alat pengendali pengereman dinamik motor induksi tiga fase $220 \mathrm{~V} / 380 \mathrm{~V}$. Tujuan dari pembuatan alat pengendali ini digunakan sebagai sistem pengendalian pengereman motor tiga fase 220V/380V yang dapat diaplikasikan pada peralatan produksi di industri. Dilihat dari hasil pengujian, waktu berhentinya putaran motor listrik tiga fase menggunakan pengereman dinamik jauh lebih cepat dibandingkan tanpa menggunakan pengereman dinamik. Waktu yang dibutuhkan untuk menghentikan putaran motor listrik tiga fase dengan beban sembilan besi (lempeng) menggunakan pengereman dinamik dibutuhkan waktu 6,8 sedangkan tanpa menggunakan pengereman dinamik waktu yang dibutuhkan 221 detik.

Kata kunci : Industri, Motor Induksi, Sistem Pengereman.

\section{ABSTRACT}

Electric motor control device affects the continuity of the production process better control at the start, controlling the speed (rotation), and the control of braking control when stopping. In particular the control of induction motor during braking, the necessary control systems that are reliable, effective, efficient and can work continuously. This study is the result of a study of design-making tool of dynamic braking control of three-phase induction motor 220V/380V. The objective of this control device is used as the motor braking control system of three-phase $220 \mathrm{~V} / 380 \mathrm{~V}$ can be applied to the production equipment in the industry. Judging from the results of the test, when the cessation of a three-phase electric motor rotation applied dynamic braking is much faster than without the use of dynamic braking. The time needed to stop the three-phase electric motor with a nine iron load (plate) using dynamic braking takes 6.8, where as without the use of dynamic braking time required 221 seconds.

Keywords: Industry, Induction Motor, Braking System.

\section{PENDAHULUAN}

Kemajuan teknologi yang pesat dewasa ini, mempengaruhi perkembangan diberbagai bidang. Kebutuhan akan teknologi pada alat produksi sangat diperlukan untuk meningkatkan keamanan dan keandalan produktifitas produksi.

Sebagian besar peralatan produksi di industri menggunakan motor listrik sebagai penggerak utama. Motor induksi tiga fase banyak digunakan oleh dunia industri karena memiliki beberapa keuntungan antara lain motor ini sederhana, murah dan mudah pemeliharaannya. Pada penggunaan motor induksi dibutuhkan sistem kontrol yang baik guna memenuhi starting motor listrik sesuai yang diharapkan dan proses menghentikan putaran motor dengan cepat, terutama aplikasi untuk konveyor.

Sebuah motor akan berhenti berputar bila diputus hubungkan dari suplai daya. Waktu yang dibutuhkan oleh motor tersebut untuk benar-benar berhenti tergantung pada kelembaman motor, beban dan friksi motor itu sendiri. Jika menginginkan untuk tingkat putaran motor berputar pelan atau berhenti, maka memerlukan tindakan pengereman.
Berdasarkan uraian diatas maka diajukanlah perancangan sistem pengereman dinamik yang digunakan untuk menghentikan putaran motor listrik $A C$ tiga fase.

\section{KAJIAN TEORI}

Motor Induksi Tiga Fase

Pada motor induksi arus rotor bukan diperoleh dari sumber tertentu, tetapi merupakan arus yang terinduksi sebagai akibat perbedaan relatif antara putaran rotor dengan medan putar yang dihasilkan oleh stator.

Motor induksi tiga fase memiliki dua komponen dasar yaitu stator dan rotor, bagian rotor dipisahkan dengan bagian stator oleh celah udara yang sempit (air gap) dengan jarak antara 0,4 mm sampai $4 \mathrm{~mm}$. Tipe dari motor induksi tiga fase berdasarkan lilitan pada rotor dibagi menjadi dua macam yaitu rotor belitan (wound rotor) adalah tipe motor induksi yang memiliki rotor terbuat dari lilitan yang sama dengan lilitan statornya dan rotor sangkar tupai (squirrel-cage rotor), yaitu tipe motor 
induksi dimana konstruksi rotor tersusun oleh beberapa batangan logam yang dimasukkan melewati slot-slot yang ada pada rotor motor induksi, kemudian setiap bagian disatukan oleh cincin sehingga membuat batangan logam terhubung singkat dengan batangan logam yang lain (Warsito, dkk., 2006:2).

\section{Pengereman Dinamik}

Pengereman dinamik digunakan untuk menghentikan putaran rotor motor induksi. Tegangan pada stator diubah dari sumber tegangan $A C$ menjadi tegangan $D C$ dalam waktu yang sangat singkat. Torsi yang dihasilkan dari pengereman tergantung pada besar arus $D C$ yang diinjeksikan pada belitan stator.

Arus searah yang diinjeksikan pada kumparan stator akan mengembangkan medan stasioner untuk menurunkan tegangan pada rotor. Oleh karena kumparan rotor terhubung singkat, arus yang mengalir menghasilkan medan magnet. Medan magnet akan berputar dengan kecepatan yang sama dengan rotor tetapi dengan arah yang berlawanan untuk menjadikan stasioner terhadap stator.

Interaksi medan resultan dan gerak gaya magnet rotor akan mengembangkan torsi yang berlawanan dengan torsi motor sehingga pengereman terjadi. Torsi pengereman yang dihasilkan tergantung pada besarnya arus injeksi $D C$ pada belitan stator, karena torsi pengereman sebanding dengan arus injeksi. Sedangkan nilai tahanan $(\mathrm{R})$ berpengaruh pada nilai kecepatan torsi pengereman terjadi. Semakin kecil nilai tahanan (R), semakin cepat torsi pengereman terjadi (Warsito, dkk., 2006:2).

\section{Dioda pengereman dinamik}

Sumber arus $D C$ yang digunakan untuk pengereman dinamik dihasilkan oleh dioda. Dioda adalah piranti elektronik yang hanya dapat melewatkan arus dalam satu arah saja. Karena itu, dioda dapat dimanfaatkan sebagai penyearah arus listrik, yaitu piranti elektronik yang mengubah arus atau tegangan bolak-balik $(A C)$ menjadi arus tegangan searah $(D C)$. Dioda yang digunakan adalah dioda penyearah gelombang penuh model jembatan dengan tegangan $220 \mathrm{~V}, 10 \mathrm{~A}$. Rangkaian dioda penyearah gelombang penuh diperlihatkan pada Gambar 1.

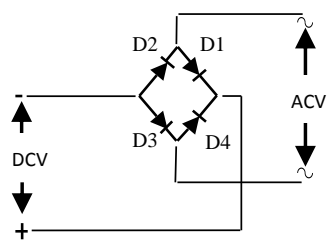

Gambar 1

Rangkaian Dioda Penyearah Gelombang Penuh

\section{Pengendali semi otomatis}

Pengendali semi otomastis adalah jenis pengendali yang menggunakan alat kendali semi otomatis berupa kontaktor magnet dan tombol tekan (push button) dilengkapi dengan pengaman. Pada pengendali semi otomatis, pengoperasian motor dilakukan melalui tombol-tombol push button untuk menggerakkan kontaktor dan selanjutnya secara otomatis langsung mengoperasikan motor listrik. Peralatan utama dalam pengendali semi otomatis adalah kontaktor magnet yang dilengkapi dengan peralatan lain seperti tombol tekan, overload, $M C B$, dan lampu indikator (pilot lamp) (Supari \& Joko., 2009: 481-482).

\section{METODE PENELITIAN}

Metode yang digunakan dalam proyek tugas akhir membuat alat pengereman dinamik motor induksi tiga fase $220 \mathrm{~V} / 380 \mathrm{~V}$ adalah :

1. Pembuatan alat pengendali motor listrik tiga fase dan dilengkapi pengereman dinamik yang digunakan untuk menghentikan putaran motor listrik.

2. Objek atau sasaran percobaan adalah motor listrik induksi tiga fase $220 \mathrm{~V} / 380 \mathrm{~V}$ yang dibebani dengan beban besi (lempeng).

\section{Langkah-Langkah Penyelesaian Masalah} Dalam pembuatan alat pengereman dinamik motor induksi tiga fase $220 \mathrm{~V} / 380 \mathrm{~V}$ terdapat langkah-langkah yang harus dilakukan adalah sebagai berikut:

1. Perencanaan, mengumpulkan data dan informasi.

2. Merencanakan rangkaian kontrol dan rangkaian daya.

3. Menentukan dan membeli komponen alat kerja dan bahan yang digunakan.

4. Proses pembuatan alat

5. Melakukan uji coba alat, apabila alat belum dapat bekerja dengan baik maka kembali ke langkah sebelumnya.

6. Mengambil data dari uji coba pada alat pengereman dinamik motor induksi tiga fase 220V/380V menggunakan rangkaian logika.

7. Mengadakan penyelesaian akhir pada alat.

\section{Kebutuhan Alat dan Bahan}

Jenis spesifikasi, satuan dan jumlah kebutuhan alat kerja yang digunakan ditunjukkan pada Tabel 1. 
Tabel 1

Alat yang Digunakan

\begin{tabular}{|c|c|c|c|c|}
\hline No & Nama Alat & Spesifikasi & Satuan & Jumlah \\
\hline 1. & Multitester & $\begin{array}{l}\text { AC-DC } 1000 \mathrm{~V}, \mathrm{DC} \\
10 \mathrm{~A}\end{array}$ & Buah & 1 \\
\hline 2. & Obeng & $(+/-), 100 \mathrm{~mm}$ & Buah & 2 \\
\hline 3. & Test Pen & 100-500VAC & Buah & 1 \\
\hline 4. & Penggaris & Besi, $50 \mathrm{~cm}$ & Buah & 1 \\
\hline 5. & Solder & $\begin{array}{l}220-240 \mathrm{VAC}, 25- \\
80 \mathrm{~W}\end{array}$ & Buah & 1 \\
\hline 6. & $\begin{array}{l}\text { Tang } \\
\text { Kombinasi }\end{array}$ & 8", $200 \mathrm{~mm}$ & Buah & \\
\hline 7. & Tang Potong & 7", $180 \mathrm{~mm}$ & Buah & 1 \\
\hline 8. & $\begin{array}{l}\text { Tang } \\
\text { Crimping }\end{array}$ & $0.75 \mathrm{~mm}^{2}-6.0 \mathrm{~mm}^{2}$ & Buah & 1 \\
\hline 9. & Kunci Shock & $8 "$ & Buah & 1 \\
\hline 10. & $\begin{array}{l}\text { Mesin Bor } \\
\text { Listrik }\end{array}$ & $\begin{array}{l}220 \mathrm{VAC}, 50-60 \mathrm{~Hz}, \\
300 \mathrm{~W}, 2200 \mathrm{rpm}\end{array}$ & Buah & 1 \\
\hline 11. & Kikir & Kasar segitiga, & Buah & 1 \\
\hline
\end{tabular}

Sedangkan jenis atau nama bahan, spesifikasi, satuan dan jumlah bahan yang digunakan ditunjukkan pada Tabel 2.

Tabel 2

Bahan yang Digunakan

\begin{tabular}{|c|l|l|l|c|}
\hline $\begin{array}{c}\text { No } \\
\text { 1. }\end{array}$ & Nama Bahan & \multicolumn{1}{|c|}{ Spesifikasi } & Satuan & Jumlah \\
\hline 2. & MCB 1 fase & $\begin{array}{l}1000 \mathrm{~mm} \times 800 \\
\mathrm{~mm} \times 5 \mathrm{~mm}\end{array}$ & lembar & 1 \\
\hline 30 & MCB 3 fase & $400 \mathrm{VAC}, 2 \mathrm{~A}$, & Buah & $16 \mathrm{~A}$ \\
\hline 4. & Kontaktor Magnit & $\begin{array}{l}25 \mathrm{~A}, 220 \mathrm{~V}, 50- \\
60 \mathrm{~Hz}\end{array}$ & Buah & 4 \\
\hline 5. & $\begin{array}{l}\text { Thermal } \\
\text { Overload Relay }\end{array}$ & $5.2 \mathrm{~A}-8 \mathrm{~A}, 690 \mathrm{~V}$ & Buah & 2 \\
\hline 6. & $\begin{array}{l}\text { Motor Listrik } 3 \\
\text { fase }\end{array}$ & $\begin{array}{l}3 \mathrm{HP}, 1425 \mathrm{rpm}, \\
50 \mathrm{~Hz}\end{array}$ & Buah & 2 \\
\hline 7. & Bridge Dioda & $10 \mathrm{~A}$ & Buah & 2 \\
\hline 8. & Push Button & $\begin{array}{l}\mathrm{NO}-\mathrm{NC}, \\
250 \mathrm{VAC}, 6 \mathrm{~A}\end{array}$ & Buah & 4 \\
\hline 9. & Skun Kabel & $1.5 \mathrm{~mm}^{2}$ & Pack & 2 \\
\hline 10. & Kabel Ties & $2.5 \times 100 \mathrm{~mm}^{2}$ & Pack & 1 \\
\hline 11. & Kabel NYAF & $1 \times 1.5 \mathrm{~mm}^{2}$ & Meter & 25 \\
\hline 12. & Kabel NYAF & $1 \times 0.75 \mathrm{~mm}^{2}$ & Meter & 35 \\
\hline 13. & Stecker Bies & $4 \mathrm{~mm}^{2}$ & Set & 25 \\
\hline
\end{tabular}

\section{HASIL DAN PEMBAHASAN}

Hasil dari penelitian ini adalah alat pengendali motor listrik yang digunakan untuk menjalankan motor listrik dan dilengkapi pengereman dinamik yang digunakan untuk menghentikan putaran motor listrik. Pada alat ini ada dua cara untuk starting motor listrik, yang pertama menggunakan pengendali semi otomatis seperti kontaktor magnet dan push button, sedangkan cara yang kedua menggunakan rangkaian logika. Dalam pembahasan ini yang akan dibahas adalah starting motor listrik menggunakan pengendali semi otomatis seperti kontaktor magnet dan push button, sedangkan starting motor listrik menggunakan rangkaian logika tidak masuk dalam pembahasan penelitian ini. Alat pengendali pengereman dinamik motor listrik diperlihatkan pada Gambar 2.

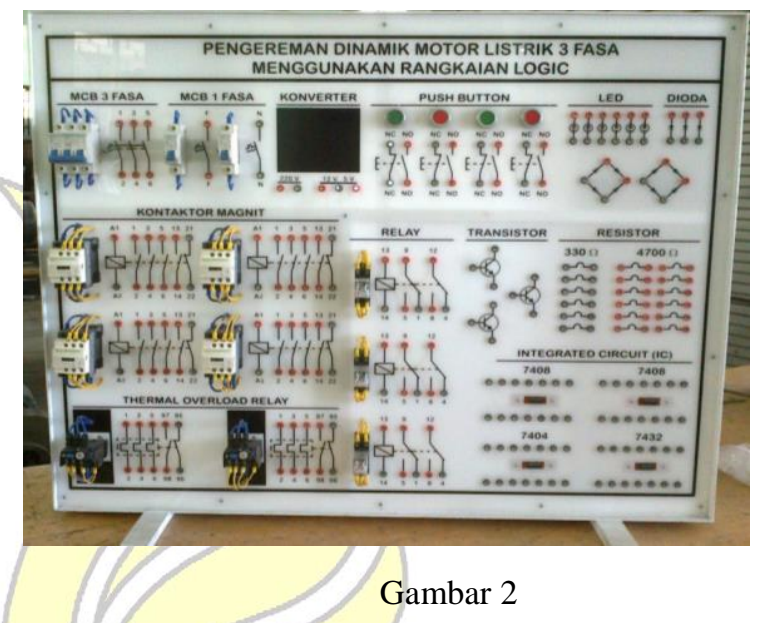

Alat pengendali pengereman dinamik motor listrik

Berikut ini adalah data spesifikasi motor listrik yang digunakan sebagai obyek atau sasaran percobaan:
a. Tegangan $220 \mathrm{~V} / 380 \mathrm{~V}$
b. $\mathrm{Hp}$ $3 \mathrm{Hp}$
c. Arus nominal : $9,2 \mathrm{~A} / 5,4 \mathrm{~A}$
d. Putaran nominal : $1425 \mathrm{rpm}$
e. Frekuensi $\longrightarrow: 50 \mathrm{~Hz}$
f. Fase : 3 fase g. Poles $: 4$

Dari data tersebut diketahui tegangan yang dibutuhkan oleh kumparan motor listrik u-x, v-y, $\mathrm{w}-\mathrm{z}$ adalah $220 \mathrm{~V}$, sedangkan tegangan line yang tersedia $220 \mathrm{~V} / 380 \mathrm{~V}$ sehing ga motor listrik tersebut dihubung bintang/star. Starting motor listrik yang digunakan untuk menjalankan motor listrik ini adalah sistem operasi Direct On Line (DOL). Motor Listrik Tiga Fase dihubungkan dengan beban besi (lempeng) diperlihatkan pada Gambar 3.

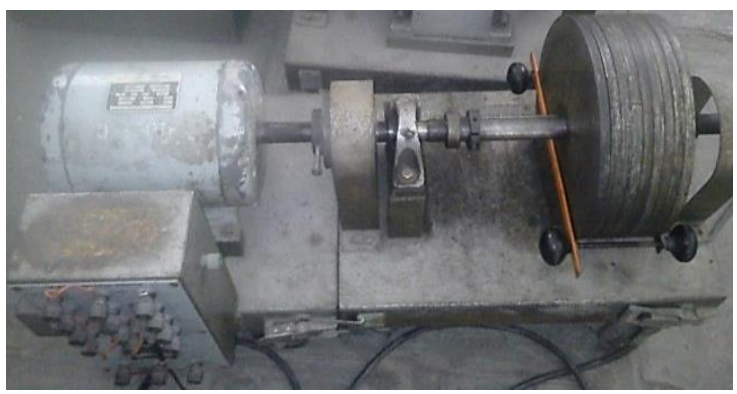


Gambar 3

Motor Listrik Tiga Fase dihubungkan dengan beban besi (lempeng)

\section{Pengujian Alat Pengereman Dinamik Motor Induksi Tiga Fase 220V/380V}

Pengujian alat ini dilakukan untuk mengetahui kinerja alat yang dibuat. Pengujian dilakukan dua macam yaitu waktu motor listrik berhenti berputar menggunakan pengereman dinamik dan waktu motor listrik berhenti berputar tanpa menggunakan pengereman dinamik. Gambar rangkaian daya dan kontrol motor listrik operasi $D O L$ dilengkapi pengereman dinamik diperlihatkan pada Gambar 4.

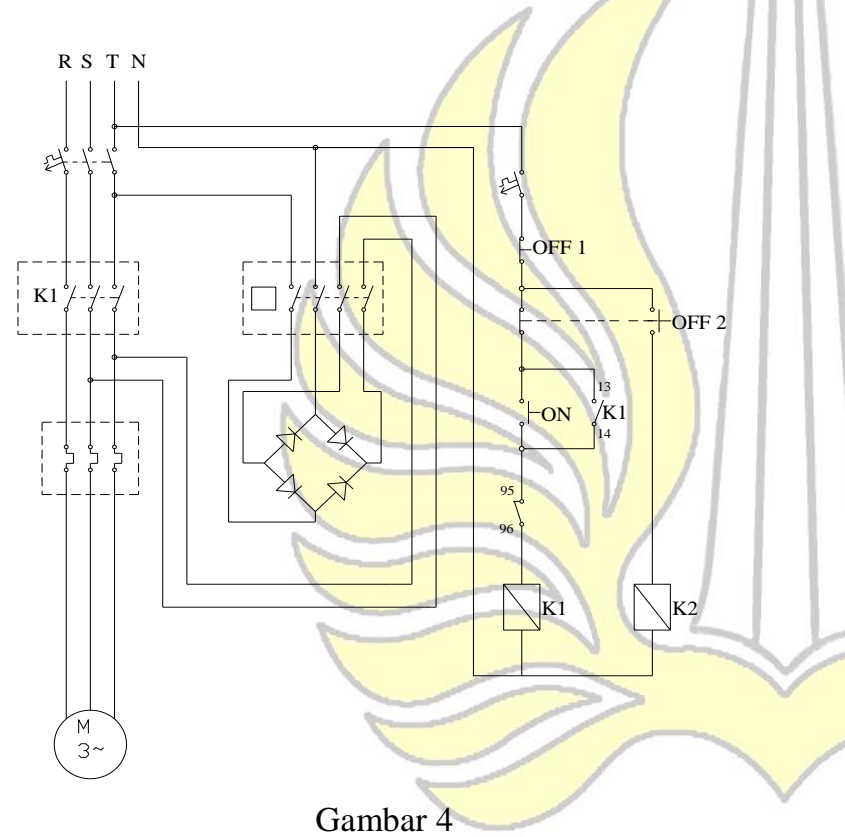

Rangkaian Daya dan Kontrol Motor Listrik Operasi DOL Dilengkapi Pengereman Dinamik

Prinsip kerja dari motor listrik tiga fase sistem operasi DOL dilengkapi pengereman dinamik yaitu :

a. Pada saat normal kontaktor K1 dan kontaktor K2 tidak bekerja, motor listrik tidak berputar.

b. Jika push button on ditekan dan dilepas kontaktor K1 bekerja dan motor listrik berputar.

c. Jika push button off 1 ditekan kontaktor K1 tidak bekerja, kontaktor K2 tidak bekerja dan motor listrik berhenti berputar tanpa pengereman dinamik.

d. Jika push button on ditekan dan dilepas kontaktor K1 bekerja dan motor listrik berputar.

e. Jika push button off 2 ditekan kontaktor K1 tidak bekerja, kontaktor $\mathrm{K} 2$ bekerja dan motor listrik berhenti berputar dengan menggunakan pengereman dinamik. f. Jika push button off 2 dilepas kontaktor K1 dan kontaktor K2 tidak bekerja, motor listrik tidak berputar.

Hasil percobaan pengujian motor listrik tiga fase berhenti berputar tanpa menggunakan pengereman dinamik dan menggunakan pengereman dinamik ditunjukkan pada tabel 3 .

Tabel 3

Hasil Percobaan Pengujian Motor Listrik Berhenti Berputar Tanpa Pengereman Dinamik dan Menggunakan Pengereman Dinamik

\begin{tabular}{|c|c|c|c|c|c|c|c|c|c|c|c|c|c|}
\hline \multirow{3}{*}{ No. } & \multirow{3}{*}{$\begin{array}{l}\text { Beban Besi } \\
\text { (Lempeng) }\end{array}$} & \multirow{3}{*}{ Rpm } & \multirow{2}{*}{\multicolumn{2}{|c|}{\begin{tabular}{|c|} 
Tanpa \\
Pengereman \\
Dinamik
\end{tabular}}} & \multicolumn{9}{|c|}{ Menggunakan Pengereman Dinamaik } \\
\hline & & & & & \multicolumn{3}{|c|}{ Percobaan 1} & \multicolumn{3}{|c|}{ Percobaan 2} & \multicolumn{3}{|c|}{ Rata-rata } \\
\hline & & & $\begin{array}{l}\text { I ac } \\
\text { (A) }\end{array}$ & $\mathrm{T}(\mathrm{s})$ & \begin{tabular}{|l|l} 
I ac & I \\
(A) & \\
\end{tabular} & $\begin{array}{l}\mathrm{Idc} \\
\text { (A) }\end{array}$ & \begin{tabular}{|c|}
$\mathrm{T}$ \\
$(\mathrm{s})$ \\
\end{tabular} & \begin{tabular}{|l|}
$\mathrm{I} \mathrm{ac}$ \\
(A)
\end{tabular} & \begin{tabular}{|l|} 
I dc \\
(A)
\end{tabular} & $\begin{array}{c}\mathrm{T} \\
(\mathrm{s})\end{array}$ & \begin{tabular}{|l|}
$\mathrm{I} a c$ \\
(A)
\end{tabular} & $\begin{array}{l}\mathrm{Idc} \\
\text { (A) }\end{array}$ & \begin{tabular}{|c|}
$\mathrm{T}$ \\
(s)
\end{tabular} \\
\hline 1. & & 1498 & 0,2 & 30.8 & 0,2 & 8,8 & 0.5 & 0,2 & 8.8 & 0.6 & 0,2 & 8.8 & 0.55 \\
\hline 2. & 1 & 1491 & 0,2 & 26 & 0,2 & 8,8 & 1.2 & 0,2 & 8.8 & 1 & 0,2 & 8.8 & 1.1 \\
\hline 3. & 3 & 1490 & 0,3 & 74 & 0,3 & 8,4 & 2.5 & 0,3 & 8.4 & 2.6 & 0,3 & 8.4 & 2.55 \\
\hline 4. & & & & 120.1 & 0,3 & 8.4 & 3.6 & 0,3 & 8.4 & 3.5 & 0,3 & 8.4 & 3.55 \\
\hline 5. & 1 & 14 & 0,3 & 174 & 0,3 & 8 & 4.5 & 0,3 & 8 & 4.5 & 0,3 & 8 & 4.5 \\
\hline o. & & & 0 & 221 & 0,3 & 8 & 6.2 & 0,3 & 8 & 6.4 & 0,3 & 8 & 6.3 \\
\hline
\end{tabular}
untuk menghentikan putaran motor induksi tiga fase tanpa menggunakan pengereman dinamik beban nol besi (lempeng) adalah 30.8 detik dan menggunakan beban penuh besi (lempeng) dibutuhkan waktu 221 detik (Tabel 3). Pada pengujian kedua waktu yang dibutuhkan untuk menghentikan putaran motor induksi tiga fase menggunakan pengereman dinamik beban nol besi (lempeng) adalah 0.55 detik dan menggunakan beban penuh besi (lempeng) dibutuhkan waktu 6.3 detik (Tabel 3). Jadi dapat disimpulkan untuk menghentikan putaran motor induksi tiga fase dengan menggunakan pengereman dinamik waktu yang dibutuhkan jauh lebih cepat dibandingkan tanpa menggunakan pengereman dinamik, untuk beban nol 30.25 detik dan untuk beban penuh 214.7 detik. Semakin besar beban yang diberikan pada motor listrik waktu yang dibutuhkan untuk berhentinya putaran motor listrik akan semakin lama.

Pengereman berguna untuk mempercepat berhentinya putaran motor dengan memperkecil arus sisa pada stator, arus yang besar akan semakin mempercepat berhentinya putaran motor. Pengereman dinamik berfungsi sebagai pemberhenti pembalik putaran dari sumber tegangan $A C$ dengan memberikan penguatan pengeluaran arus $D C$ pada 
stator motor induksi agar proses berhenti motor dapat dipercepat.

\section{PENUTUP}

\section{Simpulan}

Dari pembuatan alat dan hasil pembahasan dapat menghasilkan simpulan diantaranya :

1. Cara membuat alat pengereman dinamik adalah merencanakan gambar rangkaian yang akan dibuat, menentukan komponen yang akan digunakan, membuat rangkaian yang diaplikasikan pada alat dan melakukan uji coba untuk mengetahui kinerja alat yang dibuat.

2. Hasil kinerja alat yang dibuat adalah alat pengendali motor listrik dilengkapi pengereman dinamik yang berfungsi untuk starting motor listrik dan untuk menghentikan putaran motor listrik yang menggunakan pengereman dinamik. Jadi dapat disimpulkan untuk menghentikan putaran motor induksi tiga fase dengan menggunakan pengereman dinamik waktu yang dibutuhkan jauh lebih cepat dibandingkan tanpa menggunakan pengereman dinamik, untuk beban nol 30.25 detik dan untuk beban penuh 214.7 detik. Semakin besar beban yang diberikan pada motor listrik waktu yang dibutuhkan untuk berhentinya putaran motor listrik akan semakin lama.

\section{Saran}

Dari hasil pembuatan alat ini perlu adanya pengembangan yang lebih baik, sehingga dapat diberikan beberapa saran untuk penyempurnaan alat ini yaitu :

1. Dalam penelitian ini motor listrik yang dijadikan objek penelitian hanya satu jenis. Diharapkan untuk ke depannya bisa di coba untuk motor jenis yang lain, sehingga di dapatkan data yang lebih lengkap tentang pengereman dinamik pada motor listrik.

2. Papan alat pengendali untuk tempat komponen dibuat dari akrilik yang lebih tebal dan kerangka yang baik agar kontruksi lebih kuat.

\section{DAFTAR PUSTAKA}

Muslim, Supari dan Joko. 2009. Teknik Perencanaan dan Pemasangan Instalasi Listrik. Surabaya: Direktorat Pembinaan Sekolah Menengah Kejuruan.

Rangkaian penyearah, (Online), (http://Henryranu.files.wordpress.com, diakses 10:45 WIB, 25 Agustus 2013).

Tim Penyusun. 2002. Persyaratan Umum Instalasi Listrik 2000. Jakarta: Yayasan PUIL.

Tim Penyusun. 2005. Pedoman Tugas Akhir Program Diploma III. Surabaya: Unesa University Press.

Tim Penyusun. 2011. Menulis Ilmiah. Surabaya: Unesa University Press.

Warsito, Agung, dkk. 2006. Pengereman Dinamik Motor Tiga Fasa, (Online), (http://eprints.undip.ac.id, diakses 22:15 WIB, 10 September 2013).

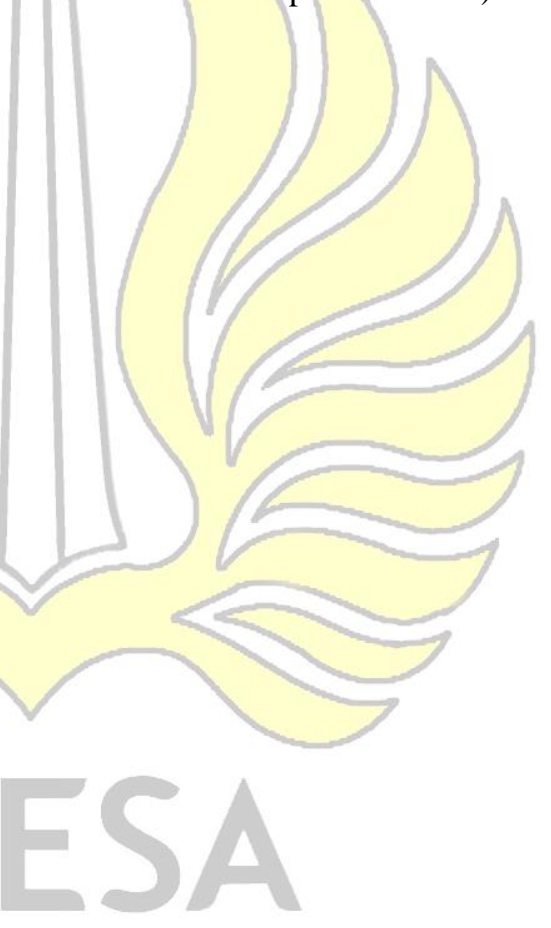

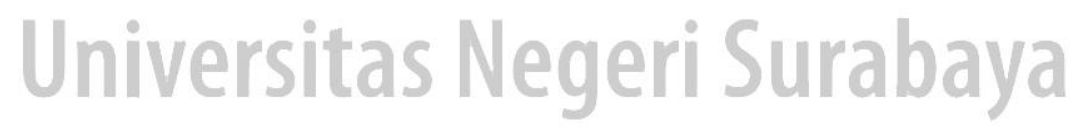

